\title{
Clinical and laboratory parameters of confirmed and probable COVID-19 patients: experience from a tertiary care hospital of Bangladesh
}

\author{
Haque HFa, Ahmed AKMS ${ }^{b}$, Habib SHc, Sulzana Md, Ghosh RPd, Shreya PD ${ }^{d}$, \\ Nessa $A^{e}$
}

\begin{abstract}
Background: Severe acute respiratory syndrome corona virus 2 (SARS-CoV-2), which was previously known as novel corona virus 2019 (2019-nCoV), causes corona virus disease 2019 (COVID-19). Since 8 March 2020, COVID -19 emerged in Dhaka city and rapidly spread throughout the country. This study evaluated the sociodemographic, clinical and laboratory parameters of confirmed and probable COVID-19 patients in a tertiary care hospital.

Methods: This cross-sectional study was conducted in BIRDEM General Hospital, Dhaka, Bangladesh from May to October 2020. Adult (>18 years) patients having clinical symptoms and signs of COVID-19, irrespective of sex were included in this study. Diagnosis was confirmed by positive reverse transcriptase polymerase chain reaction (RT-PCR) for SARS-CoV-2 from nasopharyngeal samples of patients and the disease classification was done following national guidelines.

Results: Total patients were 141with a mean age of 59.74 11.0 years; majority was from urban areas and there was male predominance. Diabetes mellitus (91.5\%) and hypertension (75.2\%) were common co-morbidities. Common clinical presentations were fever (100\%), cough (97.2\%), fatigue (88.7\%) and shortness of breath (61.7\%). Laboratory investigations revealed lymphopenia (73.8\%), elevated level of C-reactive protein (94.3\%) and positive D-dimer (99.4\%). Chest x-ray showed bilateral shadows in $73.8 \%$ cases and $42.6 \%$ had COVID pneumonia in high-resolution computed tomography (HRCT) scan of chest. Nearly three-fifths (58.9\%) of the study subjects had moderate COVID-19 and 70.92\% patients were shifted to the COVID-dedicated hospitals.

Conclusions: COVID-19 affects mostly the older males. Majority was diabetic and hypertensive. Common symptoms were fever, cough and respiratory distress. Common laboratory findings were lymphopenia, high $C R P$, positive D-dimer and bilateral shadows on lung imaging.
\end{abstract}

Key words: clinical characteristics, COVID-19, imaging, pandemic, SARS-CoV-2.

(BIRDEM Med J 2020; 10, COVID Supplement: 6-11)

Author information

a. Hasna Fahmima Haque, Assistant Professor, Internal Medicine, BIRDEM General Hospital, Dhaka, Bangladesh.

b. AKM Shaheen Ahmed, Professor, Internal Medicine, BIRDEM General Hospital, Dhaka, Bangladesh.

c. Samira Humaira Habib, Principal Research Officer, Health Economics Unit, BADAS.

d. Maliha Sulzana, Rahul Prasad Ghosh, Pradikta Das Shreya, Resident Medical Officer, Internal Medicine, BIRDEM General Hospital, Dhaka, Bangladesh.

e. Azimun Nessa, Senior Medical Officer, Internal Medicine, BIRDEM General Hospital, Dhaka, Bangladesh.

Address of Correspondence: Hasna Fahmima Haque, Assistant Professor, Internal Medicine, BIRDEM General Hospital, Dhaka, Bangladesh. Email: drfahmimahaque@gmail.com

Received: November 30, 2020

Revision received: December 6, 2020.

Accepted: December 15, 2020

\section{INTRODUCTION}

Coronavirus is an enveloped single stranded RNA virus. ${ }^{1,2}$ There are various corona viruses like severe acute respiratory syndrome coronavirus (SARS-CoV), Middle East respiratory syndrome coronavirus (MERS$\mathrm{CoV}$ ) and now, severe acute respiratory syndrome corona virus 2 (SARS-CoV-2), previously which was known as 2019-nCoV. ${ }^{3}$ This SARS-CoV-2 is responsible for corona virus disease 2019 (COVID-19). ${ }^{4}$ On 11 March 2020, COVID-19 was declared as global pandemic due to its spreading ability across the continents. ${ }^{5}$ The first COVID-19 case was reported from Wuhan, China, in December 2019. ${ }^{6}$ In Bangladesh first three cases were detected on 8 March 2020. ${ }^{7}$ 
Clinical presentation of COVID-19 varies from no symptom to fatal disease. Fever, dry cough, breathlessness and fatigue are the most common clinical manifestations. Radiographic presentations of the chest are mostly peripheral in distribution with ground-glass opacity (GGO), crazy paving, fine reticular opacity, vascular thickening and pneumonia. ${ }^{8,9}$ Here, we have described the sociodemographic, clinical, biochemical, radiological profile and treatment of confirmed and probable COVID-19 patients in a tertiary care hospital of Bangladesh.

\section{METHODS}

This cross-sectional study was done in Bangladesh Institute of Research and Rehabilitation in Diabetes, Endocrine and Metabolic Disorders (BIRDEM) General Hospital, Dhaka, Bangladesh from May to October 2020. We included all patients having clinical symptoms and signs of COVID-19, above the age of 18 years, irrespective of sex. We defined probable and confirmed COVID-19 case according to 'National Guidelines on Clinical Management of Corona Virus Disease 2019 (COVID-19) Version 7.0, published on 28 May 2020. ${ }^{10}$

Data were collected in structured questionnaire from patients and hospital records. Clinical assessment was done by measuring temperature and fever was defined as an axillary temperature of $37.5^{\circ} \mathrm{C}$ or higher. All laboratory tests were performed according to the clinical judgement. Laboratory assessments consisted of RTPCR for COVID-19, complete blood count, coagulation tests, assessment of liver and renal function, C-reactive protein, procalcitonin, lactate dehydrogenase (LDH) and ferretin. Radiological assessments included chest x-ray and high resolution computed tomography (HRCT) scan. We defined the degree of severity of COVID-19 as per national guideline. Necessary information was collected during discharge or death, if were any. Data were analyzed by Statistical Package for Social Sciences (SPSS) version 20.0 for Windows.

\section{RESULTS}

A total of 141 patients were included in this study, among them 110 were confirmed and 31 were probable case. The demographic parameter and co-morbidities are shown in Table I and II respectively. Mean age of the study subjects was $59.74 \pm 11.0$ years and most patients were from urban areas and majority were males. Regarding co-morbidities, $91.5 \%$ of subjects had diabetes, $75.2 \%$ had hypertension, $13.5 \%$ had chronic kidney disease (CKD) and $2.9 \%$ had ischemic heart disease (IHD).

Table I Demographic parameters of the study subjects $(\mathrm{N}=141)$

\begin{tabular}{lc}
\hline Characteristics & Value/parameter \\
\hline Age in years, mean (range) & $59.74 \pm 11.0(20-80)$ \\
Male: female & $2.1: 1$ \\
Urban: rural & $6.8: 1$ \\
\hline
\end{tabular}

Table II Co-morbidities among the study subjects $(\mathrm{N}=141)$

\begin{tabular}{lcc}
\hline Co-morbidities & Frequency & Percentage \\
\hline Diabetes mellitus & 129 & 91.5 \\
Hypertension & 106 & 75.2 \\
Chronic kidney disease & 19 & 13.5 \\
Ischaemic heart disease & 4 & 2.9 \\
\hline
\end{tabular}

Among clinical presentations, fever was the most common (100\%) followed by cough $(97.2 \%)$, fatigue $(88.7 \%)$ and shortness of breath (61.7). Other features are presented in Table III.

Table III Clinical characteristics/symptomatology of COVID-19 patients ( $\mathrm{N}=141)$

\begin{tabular}{lcccc}
\hline Characteristics/symptomatology & Total & $\begin{array}{c}\text { Confirmed } \\
\text { COVID- } 19(\mathrm{n}=110)\end{array}$ & $\begin{array}{c}\text { Probable } \\
\text { COVID-19 }(\mathrm{n}=31)\end{array}$ & P Value \\
\hline Fever & $141(100 \%)$ & $110(78.0 \%)$ & $31(22.0 \%)$ & $.014^{*}$ \\
Bodyache & $3(2.1 \%)$ & $3(2.1 \%)$ & 0 & .472 \\
Headache & 0 & 0 & 0 & 0 \\
Cough & $137(97.2 \%)$ & $107(75.9 \%)$ & $30(21.3 \%)$ & $.004^{*}$ \\
Shortness of breath & $87(61.7 \%)$ & $69(48.9 \%)$ & $18(12.8 \%)$ & $.003^{*}$ \\
Sore throat & $12(8.5 \%)$ & $10(7.1 \%)$ & $2(1.4 \%)$ & $.004^{*}$ \\
Loose motion & $2(1.4 \%)$ & $2(1.4 \%)$ & 0 & .670 \\
Fatigue & $125(88.7 \%)$ & $96(68.1 \%)$ & $29(20.6 \%)$ & $.001^{*}$ \\
Vomiting & $23(16.3 \%)$ & $12(8.5 \%)$ & $11(7.8 \%)$ & $.002^{*}$ \\
Abdominal pain & $2(1.4 \%)$ & $2(1.4 \%)$ & 0 & .607 \\
\hline
\end{tabular}


On laboratory investigations, we found lymphopenia in $73.8 \%$ cases. Most of the patients had elevated levels of C-reactive protein (94.3\%) and D-dimer was positive in $99.4 \%$ cases. Electrocardiogram (ECG) was abnormal (having ishchemic changes, tachy or brady arrhythmia, left ventricular hypertrophy) in 34.8\% subjects. Elevated level of alanine amino-transferase (ALT) was found in
$15.6 \%$ and aspartate amino-transferase (AST) in $24.8 \%$ cases. Chest X-ray was done in all patients, among them $73.8 \%$ had bilateral shadows and $42.6 \%$ had COVID pneumonia in HRCT scan of chest (Table IV). RT-PCR for COVID-19 was done in all subjects and the patients were classified as confirmed or probable COVID-19 depending on the result of RT-PCR as well as appropriate clinical and laboratory features.

Table IV Laboratory and imaging findings of study subjects $(\mathrm{N}=141)$

\begin{tabular}{|c|c|c|c|}
\hline Parameter & Mean \pm SD & Frequency & Percentage \\
\hline $\mathrm{TC}$ of $\mathrm{WBC} / \mathrm{cmm}$ of blood & $9981 \pm 9405$ & - & - \\
\hline Lymphopenia & - & 104 & 73.8 \\
\hline Platelet count/cmm of blood & $249635 \pm 113997$ & - & - \\
\hline ESR (mm in $1^{\text {st }}$ hour) & $38 \pm 22$ & - & - \\
\hline$\uparrow E S R$ & - & 77 & 54.6 \\
\hline $\mathrm{CRP}(\mathrm{mg} / \mathrm{L})$ & $47.70 \pm 46.38$ & - & - \\
\hline$\uparrow \mathrm{CRP}$ & - & 133 & 94.3 \\
\hline Procalcitonin (ng/ml) & $0.55 \pm 1.87$ & - & - \\
\hline$\uparrow$ Procalcitonin & - & 22 & 15.6 \\
\hline Ferretin $(\mathrm{ng} / \mathrm{ml})$ & $285.82 \pm 426.84$ & - & - \\
\hline$\uparrow$ Ferretin & - & 46 & 32.6 \\
\hline LDH U/L & $341.99 \pm 239.75$ & - & - \\
\hline$\uparrow \mathrm{LDH}$ & - & 36 & 25.5 \\
\hline \multicolumn{4}{|l|}{ D-dimer } \\
\hline Positive & - & 126 & 89.4 \\
\hline Negative & - & 15 & 10.6 \\
\hline $\mathrm{HbA1c}(\%)$ & $8.01 \pm 2.70$ & - & - \\
\hline$\uparrow H b A 1 c$ & - & 101 & 71.6 \\
\hline S. Creatinine (mg/dl) & $1.27 \pm .91$ & - & - \\
\hline 个S. Creatinine & - & 32 & 22.7 \\
\hline $\operatorname{ALT}(\mathrm{U} / \mathrm{L})$ & $41.68 \pm 37.35$ & - & - \\
\hline$\uparrow A L T$ & - & 22 & 15.6 \\
\hline AST(U/L) & $46.79 \pm 54.38$ & - & - \\
\hline$\uparrow A S T$ & - & 35 & 24.8 \\
\hline \multicolumn{4}{|l|}{ ECG } \\
\hline Abnormal & & 49 & 34.8 \\
\hline \multicolumn{4}{|l|}{ RT-PCR for COVID-19 } \\
\hline Positive & - & 110 & 78.0 \\
\hline Negative & - & 31 & 22.0 \\
\hline \multicolumn{4}{|l|}{$\operatorname{CXR}(n=141)$} \\
\hline Bilateral shadow present & & 104 & 73.8 \\
\hline \multicolumn{4}{|l|}{ HRCT chest $(n=62)$} \\
\hline COVID pneumonia suggestive & & 60 & 96.8 \\
\hline
\end{tabular}


Most patients had mild (21.3\%) to moderate (58.9\%) COVID-19; severe (12.8\%) and critical (7.1\%) cases were less common. After admission antibiotic was started in $98.58 \%$ cases, anticoagulant in $86.52 \%$ and steroid in $19.85 \%$ subjects. Over two-thirds $(70.92 \%)$ of the patients were transferred to the COVID dedicated hospitals and among the remaining patients, antiviral was given to $14.6 \%$, tocilizumab to $2.4 \%$ and

Table V Diagnosis, treatment and outcome of study subjects $(\mathrm{N}=141)$

\begin{tabular}{|c|c|c|}
\hline Parameter & Frequency & Percentage \\
\hline \multicolumn{3}{|l|}{ Diagnosis $(N=141)$} \\
\hline Confirmed & 110 & 78.0 \\
\hline Probable & 31 & 22.0 \\
\hline \multicolumn{3}{|c|}{ Classification of COVID-19 $(\mathrm{N}=141)$} \\
\hline Mild & 30 & 21.3 \\
\hline Moderate & 83 & 58.9 \\
\hline Severe & 18 & 12.8 \\
\hline Critical & 10 & 7.1 \\
\hline \multicolumn{3}{|c|}{ Treatment started after admission $(\mathrm{N}=141)$} \\
\hline Antibacterial & 139 & 98.58 \\
\hline Anticoagulant & 122 & 86.52 \\
\hline Steroid & 28 & 19.85 \\
\hline \multicolumn{3}{|c|}{$\begin{array}{l}\text { Complete treatment was given to the subjects } \\
\text { who remained at BIRDEM General Hospital } \\
(\mathrm{n}=41)\end{array}$} \\
\hline Antibacterial & 40 & 97.6 \\
\hline Anticoagulant & 36 & 87.8 \\
\hline Steroid & 20 & 48.8 \\
\hline Antiviral & 6 & 14.6 \\
\hline Tocilizumab & 1 & 2.4 \\
\hline Convalescent plasma & 1 & 2.4 \\
\hline \multicolumn{3}{|c|}{$\begin{array}{l}\text { Shifted to dedicated COVID hospital } \\
(\mathrm{N}=141)\end{array}$} \\
\hline Yes & 100 & 70.92 \\
\hline No & 41 & 29.07 \\
\hline \multicolumn{3}{|c|}{ ICU shifting needed $(n=41)$} \\
\hline Yes & 5 & 12.19 \\
\hline No & 36 & 87.8 \\
\hline \multicolumn{3}{|c|}{ Indication of ICU shifting $(n=5)$} \\
\hline ARDS & 3 & 60 \\
\hline CRS & 1 & 20 \\
\hline MOF & 1 & 20 \\
\hline
\end{tabular}

convalescent plasma to $2.4 \%$ along with antibiotic, anticoagulant and steroid. One-tenth (12.19\%) of the patients who remained at BIRDEM General Hospital needed intensive care unit (ICU) transfer (Table V). The indications of ICU transfer were acute respiratory distress syndrome (ARDS) (60\%), cytokine release syndrome (CRS) (20\%) and multi-organ failure (MOF) $(20 \%)$.

\section{DISCUSSION}

Globally until16 November 2020, there have been over 54 million COVID-19 cases confirmed with 1,316,502 deaths. From 8 March to 16 November 2020, according to the Directorate General of Health Services (DGHS) Bangladesh, 434,472 COVID-19 confirmed cases were detected by RT-PCR, including 6,215 COVID related deaths. Bangladesh is in the top $24^{\text {th }}$ position in the world. ${ }^{11}$

Our study showed that the age of the subjects ranged from 20-80 year with a mean age of 59.74 years, which was almost similar to the age of patients in different studies from China and India. ${ }^{12-17}$ Male gender was more affected than female in our study, which was consistent with the results from abroad. ${ }^{12}$ The comorbidities of our study were DM, hypertension, IHD and CKD, which were also common in Chinese population. ${ }^{18,19}$

Regarding clinical manifestations, in our study the most common symptoms were fever, dry cough, shortness of breath and fatigue; besides sore throat, diarrhea, vomiting, nausea, abdominal pain were also observed in a few cases which were more or less similar to the manifestations reported in several studies globally. ${ }^{6,}$ 16-17

Common laboratory parameters of our study subjects were normal leukocyte with lymphopenia, elevated CRP and positive D-dimer coinciding with results of numerous studies. ${ }^{6,16-17}$ Deranged liver enzymes, hyperferritinemia, high LDH, abnormal ECG were observed in some cases. Majority of our study subjects had poor glycemic control and it is one of the most important risk factor for increased morbidity and mortality in COVID-19, reported in different studies. 20, 21

Imaging findings like chest $\mathrm{x}$-ray and HRCT scan of chest varied from no shadow to extensive involvement of both lungs which were used to classify the severity 
and management of the cases as per national guideline. ${ }^{10}$, 22 Seventy percent of our patients were shifted to COVID dedicated hospitals and rest of the subjects were treated at our hospital. Among them, a few required ICU care and others were treated with anticoagulant, antibiotics, antivirals, steroid and tocilizumab.

\section{Limitations}

It was a single center study with small sample size. We could not correlate severity of the disease with laboratory parameters and outcome, as most of our patients were shifted to COVID dedicated hospitals and a few of them to the ICU. Therefore, we could not follow up them properly. Extended follow up could provide more information about the clinical progression, treatment course and disease outcome. Further multicenter, large-scale study will strengthen the findings of this study.

\section{Conclusion}

From the findings of present study, it can be concluded that, COVID-19 affected predominantly elderly male patients. Most of them were diabetic and hypertensive. Common symptoms were fever, cough, fatigue and shortness of breath. Important laboratory findings were lymphopenia, high CRP, positive D-dimer, poor glycemic status and bilateral shadows on lung imaging. Most of them were shifted to the COVID dedicated hospitals and the remaining subjects were treated with anticoagulants, antibiotics, steroid, antivirals and tocilizumab.

Authors' contribution: HFH planned the research, searched literature and drafted the manuscript. AKMSA revised the manuscript. SHH analyzed data. MS, RPG, PDS, AN collected data. All authors read and approved the final version of the manuscript for submission.

Conflict of interest: Nothing to declare.

\section{REFERENCES}

1. Su S, Wong G, Shi W, Liu J, Lai ACK, Zhou J.et al. Epidemiology, Genetic Recombination and Pathogenesis of Coronaviruses. Trends Microbiol2016;24(6): 490-502.

2. Weiss SR, Navas-Martin S.Coronavirus pathogenesis and the emerging pathogen severe acute respiratory syndrome coronavirus. Microbiol MolBiol Rev 2005;69(4):635-64.

3. CDC.2019 Novel Coronavirus, Wuhan, China.CDC. Available at https://www.cdc.gov/ coronavirus/2019-ncov/about/ index.html. January 26, 2020.
4. World Health Organization.Director-General's remarks at the media briefing on 2019-nCoV on 11 February 2020. http:// www.who.int/dg/speeches/detail/who-director-general-sremarks-at-the-media-briefing-on-2019-ncov-on-11-february2020.

5. World Health Organization. Coronavirus disease 2019 (COVID-19) situation report -75 . Geneva, Switzerland: WHO, 2020.

6. GuanWJ, NiZY, HuY, W.-H. Liang, C.-Q. Ou, J.-X. He, et al. Clinical characteristics of coronavirus disease 2019 in China. N Engl J Med 2020; 382:1708-20.

7. WHO Bangladesh COVID-19 Situation Report \#10. https:// www.who.int/bangladesh/emergencies/coronavirus-disease(covid19)update/coronavirus-disease-(covid-2019)bangladesh-situation-reports

8. CDC. 2019 Novel Coronavirus, Wuhan, China: Symptoms. CDC. Available at https://www.cdc.gov/coronavirus/2019ncov/about/symptoms.html. January 26, 2020.

9. Bai HX, Hsieh B, Xiong Z, Halsey K, Choi JW, Tran TML, et al. Performance of radiologists in differentiating COVID-19 from viral pneumonia on chest CT. Radiology 2020 Mar 10. doi: $10.1148 /$ radiol.2020200823

10. National Guidelines on Clinical Management of Coronavirus Disease 2019 (COVID-19) Version 7.0 28 May 2020.

11. WHO BangladeshCOVID19SituationReport\#38. https:// www.who.int/bangladesh/Emergencies/coronavirus-disease(covid-19)-update/coronavirus-disease-(covid-2019)Bangladesh-situation-reports.

12. Liu K, Fang YY, Deng Y, Liu W, Wang MF, Ma JP et al. Clinical characteristics of novel coronavirus cases in tertiary hospitals in Hubei province. Chin Med J (Eng1) 2020;133:1025-103.

13. Shi H, Han X, Jiang N, Cao Y, Alwalid O, Gu J et al. Radiological findings from 81 patients with COVID-19 pneumonia in Wuhan, China: a descriptive study. Lancet Infect Dis 2020, 20: 425-34.

14. Coronavirus disease 2019 (COVID-19): current literature and status in India. (2020). Accessed:April 12, 2020: https:// www.preprints.org/manuscript/202004.0189/v1.

15. Wu Z, McGoogan JM. Characteristics of and important lessons from the coronavirus disease 2019 (COVID-19) outbreak in China: summary of a report of 72314 cases from the Chinese Center for disease control and prevention. JAMA 2020; 323:1239-42.

16. Wang W, Xu Y, Gao R, Lu R, Han K, Wu G, Tan W. Detection of SARS-Cov-2 in different types of clinical specimens. JAMA 2020; 323:1843-4.

17. Liu Y, Du X, Chen J, Luo M, Chen L, Zhao Y et al. Neutrophilto-lymphocyte ratio as an independent risk factor for 
mortality in hospitalized patients with COVID-19. J Infect 2020;8:6-12.

18. Guan WJ, Liang WH, Zhao Y, Liang HR, Chen ZS, Li YM, et al. Comorbidity and its impact on 1590 patients with COVID19 in China: a nationwide analysis. Eur Respir J 2020;55(5):2000547.

19. Yang J, Zheng Y, Gou X, Pu K, Chen Z, Guo Q, et al. Prevalence of comorbidities and its effects in patients infected with SARS-CoV-2: a systematic review and metaanalysis. Int J Infect Dis 2020;94:91-5.
20. Zhu L, She Z-G, Cheng X, Qin J-J, Zhang X-J, Cai J et al. Association of blood glucose control and outcomes in patients with COVID-19 and pre-existing type 2 diabetes. Cell Metab. 2020; 31(6): 1068-77.

21. Sanyaolu A, Okorie C, Marinkovic A, et al. Comorbidity and its Impact on Patients with COVID-19. SN Compr Clin Med. 2020;1-8.

22. Li K, Fang Y, Li W, Pan C, Qin P, Zhong Y, Liu X, Huang M, et al. CT image visual quantitative evaluation and clinical classification of coronavirus disease (COVID-19). Eur Radiol 30, 2020;4407-16. 